

\title{
EVALUATION OF CONTROL STRATEGIES USING AN OXIDATION DITCH BENCHMARK
}

\author{
A. Abusam*, K.J. Keesman*, H. Spanjers**, G. van Straten*, and K. Meinema*** \\ * Systems and Control Group, Wageningen University, Bomenweg 4, 6703 HD Wageningen, The \\ Netherlands. \\ ** AEST, Environmental Technology, Wageningen University, 6700 EV Wageningen, The Netherlands. \\ *** DHV Water BV, P.O. Box 484, 3800 AL Amersfoort, The Netherlands.
}

\begin{abstract}
This paper presents validation and implementation results of a benchmark developed for a specific full-scale oxidation ditch wastewater treatment plant. A benchmark is a standard simulation procedure that can be used as a tool in evaluating various control strategies proposed for wastewater treatment plants. It is based on model and performance criteria development. Testing of this benchmark, by comparing benchmark predictions to real measurements of the electrical energy consumptions and amounts of disposed sludge for a specific oxidation ditch WWTP, has shown that it can (reasonably) be used for evaluating the performance of this WWTP. Subsequently, the validated benchmark was then used in evaluating some basic and advanced control strategies. Some of the interesting results obtained are the following: (i) influent flow splitting ratio, between the first and the fourth aerated compartments of the ditch, has no significant effect on the TN concentrations in the effluent, and (ii) for evaluation of long-term control strategies, future benchmarks need to be able to assess settlers' performance.
\end{abstract}

\section{KEYWORDS}

Benchmark, carrousel, control strategies, modeling, oxidation ditch.

\section{INTRODUCTION}

In the last few decades, the public has become more aware about the causes of the increasing pollution problems in receiving waters. This has led to enforcements of very strict standards for the effluents of wastewater treatment plants (WWTP) (EC, 1999; UNEP, 1999). For achieving these strict standards, at minimum costs, numerous control strategies have been proposed for use in controlling the performance of WWTP's (Lindberg, 1997; Lukasse, 1999; Singman, 1999; Weijers, 2000). However, a thorough evaluation of these control strategies by carrying out experimental works is obviously not possible. Wastewater treatment processes are very complex processes that are subject to large disturbances in influent load and composition. Furthermore, it is practically not possible to prevent the effect of the rapidly changing environmental conditions surrounding these processes. Therefore, computer simulations offer a useful approach to solve this problem. 
Recently, Keesman et al., (1997) and Spanjers et al., (1997) have pointed out the need for a rigorous methodology (benchmarking) for evaluating and comparing the numerous control strategies proposed for WWTP's. The idea to produce a standardised simulation benchmark, as a tool for evaluating the performance of activated sludge WWTP's, was then developed further by the IWA Task Group on Respirometry together with the European Co-operation in the field of Scientific and Technical Research (COST) 682/624 (Copp, 2000). The COST Group defines the benchmark as "A protocol to obtain a measure of performance of control strategies for activated sludge plants based on numerical, realistic simulations of the controlled plant". According to this definition, the benchmark will be consisting of a description of the plant layout, a simulation model and definitions of (controller) performance criteria.

The purpose of this paper is to validate and demonstrate the implementation of a benchmark developed for a full-scale oxidation ditch WWTP located in Rotterdam, The Netherlands. The paper layout is as follows. In the next section, a brief description of the various components of the benchmark will be given. Then the benchmark will be validated using real data. After that, implementation of the benchmark will be demonstrated by evaluating three basic and one advanced control strategies. Finally, conclusions will be presented.

\section{BENCHMARKING A SPECIFIC WWTP}

\section{Plant layout}

The WWTP studied here is a 300000 p.e. carrousel located in Rotterdam, The Netherlands. This plant consists of two main parallel treatment lines. Each line has two primary settlers, one selector, one carrousel $(406.25 \mathrm{~m} \mathrm{x}$ $8 \mathrm{~m} \mathrm{x} 4 \mathrm{~m}$ deep), and three circular secondary settlers (each has a diameter $=52.9 \mathrm{~m}$ and side wall depth $=2 \mathrm{~m}$ ). Each carrousel has four surface aerators. About $67 \%$ of the combined effluent flow of the two primary settlers is directed to the first aerated compartment and the rest to the fourth aerated compartment.

\section{Model development and validation}

A single treatment line was modeled as a reactor (carrousel) plus a secondary settler. $\cdot$ Reactor hydraulics were approximated by a loop-of-equal CSTR's, biochemical processes were modeled by the activated sludge model (ASM) No.1 (Henze et al., 1987), whereas the secondary settler was modeled as a 10-layers non-reactive settler, according to Takács et al. (1991). As suggested by Abusam and Keesman (1999), 10 CSTR's were used in modeling the reactor.

This model was previously calibrated for data obtained at constant water temperature of $22{ }^{\circ} \mathrm{C}$, in July-August 1992 (see Abusam et al., 2000a). In the calibration, values of the following three parameters were optimized: the aeration constant $\left(k=K_{L} a \cdot V_{A}\right), \eta_{g}$ and $\eta_{h}$. To validate this previously calibrated model with data obtained at a different season of the year (January-February 1993), however, recalibration of the parameters for the effect of temperature was needed. In the recalibration stage, kinetic parameters and oxygen transfer rate were made dependent on water temperature, using the Arrhenius relationship (Eqn. 1).

$$
r_{T}=r_{20} \theta^{(T-20)}
$$

where $\theta$ is the temperature-activity coefficient to be calibrated, and $r_{T}$ is reaction rate at $\mathrm{T}^{\circ} \mathrm{C}$. Following Weijers (2000), only some kinetic parameters were optimized for the effect of temperature, whereas the rest of the kinetic parameters were assigned the default value of $\theta=1.04$ suggested by Metcalf \& Eddy (1991). Kinetic parameters, which were optimized, were divided into the following three groups: (i) $\mu_{H}, b_{H}, k_{H}, K_{X}$ and $k_{A}$ (ii) $\mu_{A}$ and $b_{A}$ and (iii) $K_{N H}$. Each group was assigned the same temperature coefficient. Rate of oxygen transfer (here $k=K_{L} a \cdot V_{A}$ ) was also made temperature dependent. Thus, values of four temperature coefficients were optimized, using the data obtained for January 1993, during which water temperature ranged from 11.4 to 12.1 
${ }^{\circ} \mathrm{C}$ (Schieland, 1994). Optimum temperature coefficients $(\theta)$ obtained for the three groups of kinetic parameters and the oxygen transfer rate were found to be: 1.0, 1.08, 1.08 and 1.0179, respectively. Using parameter values obtained in the recalibration stage, the model was then verified by the data collected in February 1993 (Schieland, 1994).

Fig. 1 shows the recalibration results, whereas Fig. 2 presents the validation results. From these figures, it is clear that the recalibrated model describes reasonably the system behavior. However, it is also apparent that system dynamics are not very well predicted, especially in the first half of the test period. Furthermore, the residues are not randomly distributed; hence the model may not have the content needed to describe the finer details. Nonetheless, the model predictions are acceptable enough to be used for evaluating integrated performance indices as described in the next section.
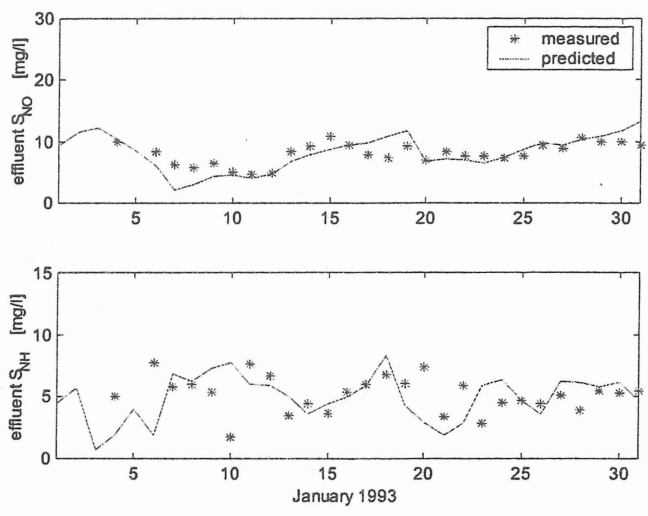

Fig. 1, Results of model recalibration for temperature effects
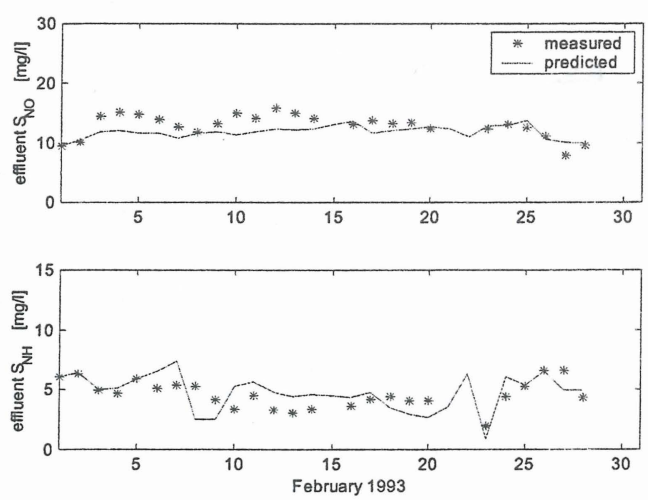

Fig. 2, Results of model validation

\section{Performance criteria}

The performance criteria developed for this oxidation ditch benchmark are more or less the same as those proposed by COST and IWA Working Groups (see COST, 2000). Exceptions are the necessary modifications made in the energy equations. Oxidation ditches often use mechanical aerators, which are different from air diffusers used in conventional activated sludge systems. Furthermore, in oxidation ditches there are no special pumps used for internal recirculation, as the mechanical aerators themselves perform this task. Therefore, the equations for $\mathrm{AE}$ (aeration energy index, $\mathrm{kWh} / \mathrm{d}$ ) and $\mathrm{PE}$ (pumping energy index, $\mathrm{kWh} / \mathrm{d}$ ) were modified. For more about the modification made in the performance indices see Abusam et al., (2000b).

\section{Testing of the benchmark}

In validating the benchmark, real measurements of $A E$ and $D S$ (disposed sludge index, $\mathrm{kg} / \mathrm{d}$ ) were compared with the benchmark predictions (Fig. 3). Note that values reported in this figure are for the whole treatment plant (i.e. the two treatment lines). As can be seen, the benchmark prediction of both $A E$ and $D S$, is generally acceptable. Deviation of benchmark predictions from the real measurements is, on average, less than 10 per cent. The relatively poor fit obtained during the first 10 days can be attributed to low initial biomass concentrations.
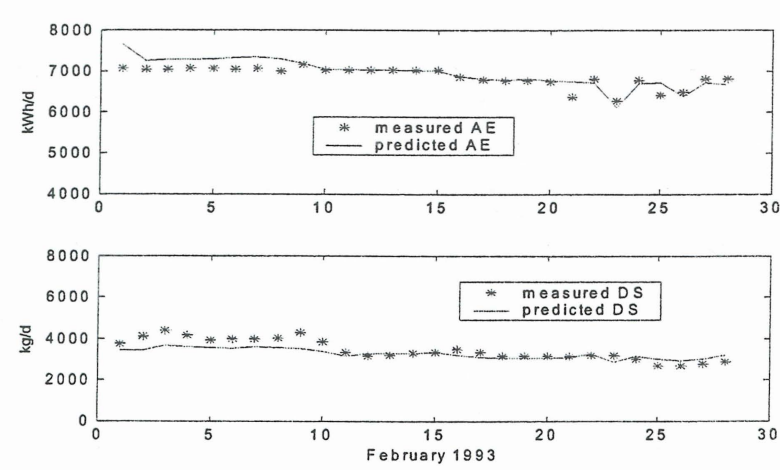

Fig. 3, Results of the benchmark validation. 
Except in these 10 days, changes in the performance indices seem to be predicted fairly well by the benchmark. It should be noted, however, that the natural variations in the observed data is too limited to allow for a more thorough validation.

\section{IMPLEMENTATION OF THE BENCHMARK}

The procedure for evaluating the short-term control strategies was the following. First, a 100-day steady-state simulation was conducted to determine the initial conditions. Secondly, dynamic simulations were performed using three scaled weather files (dry, rain and storm weather). That is, weather files proposed by COST were scaled up to suit this particular plant. Thirdly, the outputs of the last seven days were used to assess: (i) violation of effluent constrains and (ii) effluent quality costs, which is expressed in terms of performance indices. Finally, the performance indices were expressed in monetary terms (Euros). Because the long-term control strategy was evaluated over the whole year, the steps two (use of weather files) and three (evaluation over seven days) of the procedure described above were skipped in the long-term evaluation.

\section{Evaluation of the short-term control strategies}

Control strategy No. 1: Splitting of the influent flow. In each treatment line of the WWTP, effluent flows of the two primary settlers are usually combined in one stream, which is then divided between the first and the fourth aerated compartments of the oxidation ditch. Usually about $67 \%$ of the ditch influent is directed towards the first aerated compartment, while about $33 \%$ is taken to the fourth aerated compartment. In order to find the optimum splitting ratio that maximizes $T N$ removal, simulations were carried out at splitting ratio ranging from zero to one (Table 1). As this table shows, concentration of $T N$ in the effluent is not significantly affected by the change in the splitting ratio. In fact, this is expected, because the whole influent flow represents only a small fraction of the flow that recirculates around the ditch. In oxidation ditches, recirculation flow is usually about 60 -120 times of the influent flow, depending on the dimensions of the ditch. Thus, regarding the concentration of the effluent $T N$, the ratio of splitting the influent flow between the first and the fourth aerated compartments makes no difference. However, by not joining the effluent flows of the two primary settlers, some saving in the design and operational costs can be made, as effluent of primary settlers will no longer be combined in one stream. Thus, the control strategy No. 1 is to operate the WWTP at a splitting ratio equal 0.5 . That is, effluent of one primary settler is directed to the first aerated compartment, whereas effluent of the other settler is taken to the fourth aerated compartment. Assessment results of this control strategy are reported in Table 2.

Table 1 Effect of splitting the influent flow $\left(Q_{i n}\right)$ between the first aerator $\left(Q_{1}\right)$ and the fourth aerator $\left(Q_{4}\right)$

\begin{tabular}{|l|l|l|l|l|l|l|l|l|l|l|l|}
\hline$Q_{4} / Q_{\text {in }}$ & 0.0 & 0.1 & 0.2 & 0.3 & 0.4 & 0.5 & 0.6 & 0.7 & 0.8 & 0.9 & 1.0 \\
\hline $\begin{array}{l}\text { Average } \\
\mathrm{TN}_{\text {eff }}(\mathrm{mg} / \mathrm{l})\end{array}$ & 10.84 & 10.82 & 10.78 & 10.75 & 10.73 & 10.70 & 10.67 & 10.64 & 10.62 & 10.59 & 10.57 \\
\hline
\end{tabular}

Control strategy No. 2: RAS. Control strategy No. 2 is intended to optimise the recirculated activated sludge $(R A S)$ with respect to $E Q$ and the other performance indices. RAS is a ratio of the recirculated amount of sludge to the influent flow. To find the optimum value of $R A S$, the plant was simulated for different values of $R A S(0: 0.1: 1.0)$. Fig. 4 shows the effect of $R A S$ on the performance indices, which are reported in Euro. From this figure it can be seen that the costs of the pumping energy $(P E)$ steadily increases with the increase in the $R A S$ ratio, whereas $E Q$ and TSP (total sludge production index, $\mathrm{kg} / \mathrm{d}$ ) decrease, especially beyond $R A S$ equals 0.6 , relatively slowly. However Fig. 4 also shows that $\mathrm{PE}$ cost is negligible, compared to the costs of $E Q$ or TSP. Thus, it

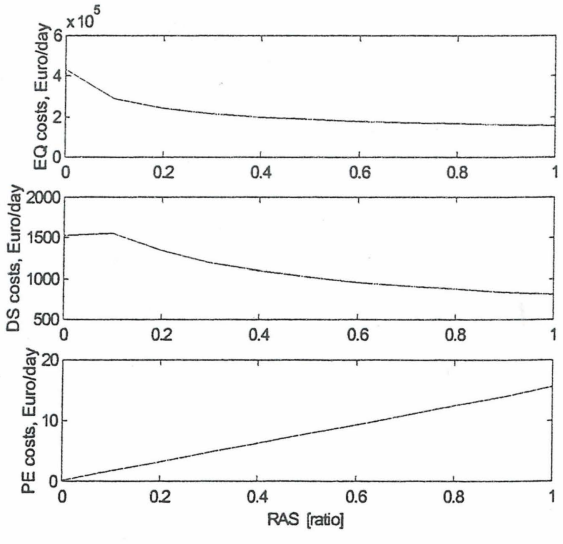

Fig. 4, Effect of RAS on the performance indices expressed in Euro's/d. 
is clear that some operational costs, in terms of $E Q$ and TSP costs, can be saved, when the plant is operated at $R A S$ equal 1 . This control strategy was then implemented as the control strategy No. 2. As before, evaluation results are reported in Table 2.

Control strategy No. 3: Aeration pattern. Fig. 5 depicts the fixed OFF-ON aeration patterns during the calibration period, July-August 1992 (DHV Water, 1993). From a first glance at this figure, it may seem that complete shutdown of the aerator No. 4 is possible. Fig. 5 shows that the first and the second aerators work at full capacity all the day, whereas the third and fourth aerators work at low capacity all the day. In fact, the fourth aerator works only few hours a day. Therefore, it was decided to shutdown completely the aerator No. 4 , and to find a new operational pattern for the aerator No. 3 that is equivalent to both the operational pattern of the third and fourth aerators, with respect to amount of oxygen needed for maximum $T N$ removal. To develop the operational pattern of the aerator No. 3, it was assumed that ammonia concentrations in the effluent should be between optimum bounds that maximize TN removal (see also Lukasse et al., 1999). Optimum ammonia bounds were found to be equal to 1.2 and 2.25 , which were used in finding out the operating pattern of the aerator No. 3. Then, the control strategy No. 3 was implemented. As before, assessment
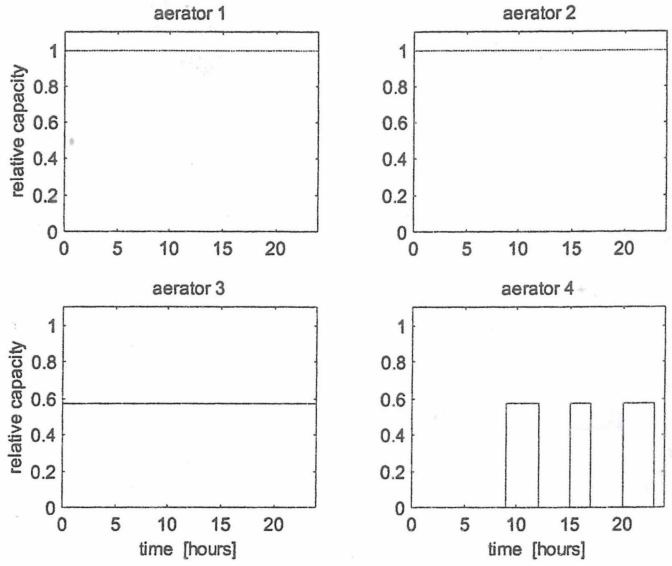

Fig. 5, Operational patterns for the four aerators in July-August 1992 (DHV Water 1993) results are reported in Table 2.

Table 2 summarizes the results obtained from implementing the three short-term control strategies, and compared that to the real performance of the treatment plant (reference performance). As can be seen, in general, all the performance indices and percent time of violations for the implemented control strategies are almost the same as that for the reference performance of the plant. An exception is the saving in the cost of $A E$ (about 100 Euro/d) that can be made, when implementing the control strategy No. 3. However, it is highly uncertain that this saving in AE costs can really be made. This because that in a previous study (Abusam et al., 2000c) we have found that due to uncertainty in the parameter values, deviation of the performance from the nominal values can reach $+473 \%,-64 \%,+544 \%$ and $+64 \%$ for indices $E Q, A E, T S P$ and $D S$, respectively. However, here should be clear that our intention was not to develop new control strategies, but rather to demonstrate the use of the benchmark.

\section{Evaluation of a long-term control strategy}

As an example of the applicability of the benchmark methodology to evaluate a long-term control strategy, the control scheme proposed by Lukasse (1999), for yearly average $T N$ control (see Fig. 6) was partly implemented. The main idea behind this proposed control strategy is that saving can be made in the costs of the $D S$ and probably in the costs of $A E$, by optimising the amount of biomass $(M L S S)$ needed during the different seasons of the year. It is well known that biomass activity depends on the seasonal change in water temperature. In order to meet the yearly $T N$ standard for the effluent, at minimum costs, Lukasse (1999) suggests to manipulate MLSS according to the seasonal needs.

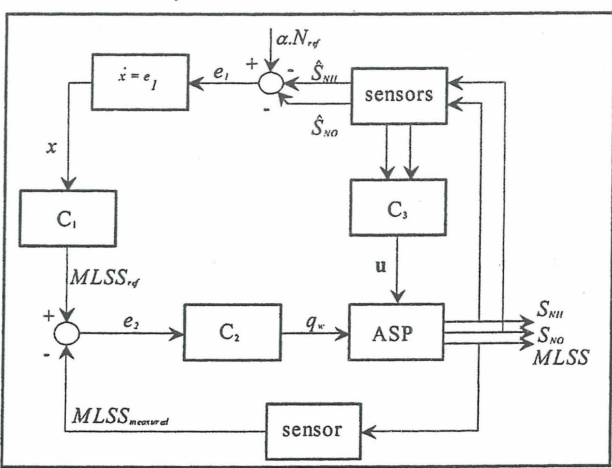

Fig. 6, Feedback control loop for yearly-averaged TN control (Lukasse, 1999) 
Table 2 Short-term assessment of three basic control strategies.

\begin{tabular}{|c|c|c|c|c|c|c|c|c|c|c|c|}
\hline \multirow{2}{*}{\multicolumn{2}{|c|}{ Index }} & \multirow{2}{*}{$\begin{array}{l}\text { Reference: } \\
\text { Splitting = 0.67; } \\
R A S=1 \\
\text { Aeration (Fig. 5) }\end{array}$} & \multicolumn{3}{|c|}{$\begin{array}{c}\text { Strategy No. 1: } \\
\text { Splitting ratio }=0.50 ; R A S=1\end{array}$} & \multicolumn{3}{|c|}{$\begin{array}{c}\text { Strategy No. 2: } \\
\text { Splitting ratio }=0.67 ; R A S=1\end{array}$} & \multicolumn{3}{|c|}{$\begin{array}{c}\text { Strategy No. 3: } \\
\text { Splitting ratio }=0.67 ; R A S=1\end{array}$} \\
\hline & & & $\begin{array}{l}\text { Dry } \\
\text { weather }\end{array}$ & $\begin{array}{l}\text { Rainy } \\
\text { weather }\end{array}$ & $\begin{array}{l}\text { Stormy } \\
\text { weather }\end{array}$ & $\begin{array}{l}\text { Dry } \\
\text { weather }\end{array}$ & $\begin{array}{l}\text { Rainy } \\
\text { weather }\end{array}$ & $\begin{array}{l}\text { Stormy } \\
\text { weather }\end{array}$ & $\begin{array}{l}\text { Dry } \\
\text { weather }\end{array}$ & $\begin{array}{l}\text { Rainy } \\
\text { weather }\end{array}$ & $\begin{array}{l}\begin{array}{l}\text { Stormy } \\
\text { weather }\end{array} \\
\end{array}$ \\
\hline \multicolumn{2}{|l|}{$E Q[\mathrm{~kg} / \mathrm{d}]$} & 5149 & 4331 & 5805 & 4865 & 4364 & 5832 & 4896 & 4444 & 5757 & 4998 \\
\hline \multicolumn{2}{|c|}{$A E[\mathrm{kWh} / \mathrm{d}]$} & 7110 & 8001 & 8011 & 8026 & 8013 & 8021 & 8037 & 6582 & 6629 & 6608 \\
\hline \multicolumn{2}{|c|}{$P E[\mathrm{kWh} / \mathrm{d}]$} & 251 & 250 & 341 & 291 & 250 & 341 & 291 & 250 & 341 & 291 \\
\hline \multicolumn{2}{|l|}{$D S[\mathrm{~kg} / \mathrm{d}]$} & 1401 & 2284 & 2717 & 2691 & 2294 & 2727 & 2702 & 2534 & 3024 & 2969 \\
\hline \multicolumn{2}{|c|}{$E Q$ costs $[$ Euro/d] } & 154470 & 129930 & 174160 & 145950 & 130930 & 174960 & 146880 & 140740 & 176840 & 156430 \\
\hline \multicolumn{2}{|c|}{$A E$ costs $[$ Euro/d] } & 512 & 580 & 580 & 580 & 580 & 580 & 580 & 480 & 480 & 480 \\
\hline \multicolumn{2}{|c|}{$P E$ costs $[$ Euro/d] } & 18 & 18 & 25 & 21 & 18 & 24.6 & 21 & 18 & 24.6 & 21 \\
\hline \multicolumn{2}{|c|}{$D S$ costs [Euro/d] } & 813 & 1325 & 1576 & 1561 & 1331 & 1582 & 1567 & 1555 & 1842 & 1817 \\
\hline \multirow{5}{*}{ 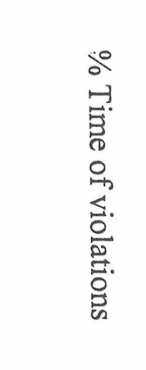 } & $S_{N H}$ & & 18.0 & 24.3 & 19.6 & 18.0 & 23.7 & 19.2 & 17.3 & 22.3 & 18.6 \\
\hline & $T N$ & & 0 & 0 & 0 & 0 & 0 & 0 & 0 & 0 & 0 \\
\hline & $B O D_{5}$ & & 0 & 0 & 0 & 0 & 0 & 0 & 0 & 0 & 0 \\
\hline & $C O D$ & & 0 & 0 & 0 & 0 & 0 & 0 & 0 & 0 & 0 \\
\hline & TSS & & 0 & 0 & 0 & 0 & 0 & 0 & 0 & 0 & 0 \\
\hline
\end{tabular}

Effluent constraints are 4, 18, 25, 125 and 30 for $N_{4}-N, T N, B O D_{5}, C O D$ and TSS, respectively.

Indicative unit price: for $E Q$ is 30 Euro $/ \mathrm{kg}$; for $A E$ and $P E$ is $0.072 \mathrm{Euro} / \mathrm{kWh}$; and for $D S$ is 0.58 Euro $/ \mathrm{kg}$.

Aeration pattern for control strategies 1 and 2 is presented in Fig. 5, whereas for strategy 3 bounds of 1.2-2.25

for effluent ammonia were used. 
Lukasse's control strategy was implemented without the controller $C_{3}$, because the interest was in the long-term effects only. In stead, the fixed ON-OFF patterns of the aerators (Fig. 5), was used. The Ziegler and Nichols method was used in designing the controller $C_{1}$, as $\mathrm{P}$ controller, and the controller $C_{2}$, as PI controller. For comparison, performance data with the existing strategy were obtained from the same full-scale oxidation ditch plant for the whole year of 1993 (Schieland, 1994). Because there was no information about the actual aeration, it was assumed that the fixed OFF-ON pattern for the calibration period in 1992 (see Fig. 5) was also applied in 1993.

Fig. 7 presents effluent TN concentrations, over the whole year, whereas Fig. 8 presents both MLSS concentrations and $W A S$ rates that are needed for achieving about $9 \mathrm{mg} / 1$ yearly average $T N$. Table 5 compares the results obtained from implementing the control strategy proposed by Lukasse (1999) to the real performance. Note that here all sensors were assumed to be perfect (i.e. sensor dynamics and time delays were neglected).
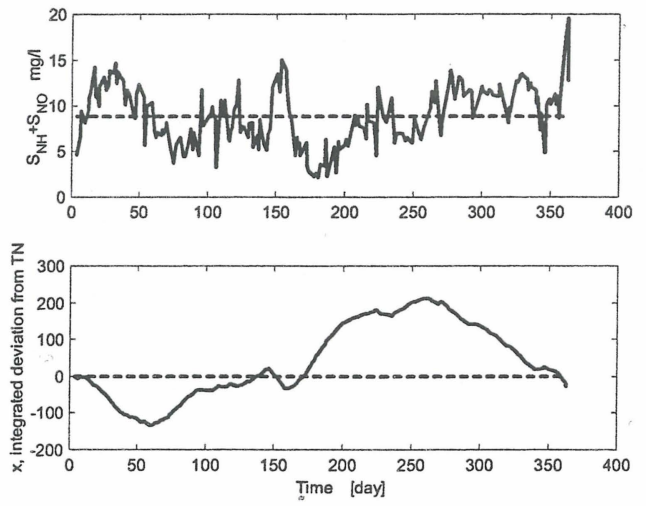

Fig. 7, Profile of effluent TN obtained by Lukasse (1999) scheme, with $\alpha N_{\text {ref }}=9 m g / l$.
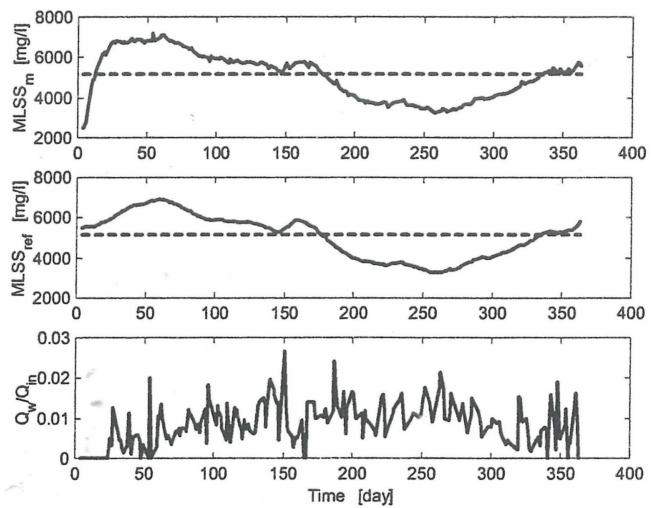

Fig. 8, Profile of effluent MLSS and WAS as obtained for the control strategy proposed by Lukasse (1999).

As can be seen from Fig. 7, the yearly average $\mathrm{S}_{\mathrm{NH}}+\mathrm{S}_{N O}$ of $9 \mathrm{mg} / 1$ was met. However, Fig. 8 shows this was met by keeping MLSS at high values $(>6000 \mathrm{mg} / \mathrm{l})$, all through the first half of the year. With high MLSS concentrations for such a long time, however, outside the validity range of the model, the settler might not function properly. However, evaluation of the settler performance is beyond the scope of this benchmark.

From the comparison presented in Table 5, it is clear that a substantial reduction in the costs of $D S$ (about 2500 Euro/day) can be achieved using Lukasse's control strategy. However, the same table shows that no savings can be made in the costs of $A E$. But this is expected since the controller $C_{3}$ was not implemented. Also the relatively long time of violation of the $\mathrm{NH}_{4}-\mathrm{N}$ constraints (see Table 5) can be attributed to the fact $C_{3}$ was not implemented. However, Table 5 also shows that Lukasse's control strategy reduces $T N$ violation time. In short, Lukasse's control strategy seems to be very promising.

\section{CONCLUSIONS}

A benchmark was developed for a specific fullscale oxidation ditch WWTP. Testing showed that the benchmark could reasonably be used for evaluating the
Table 5 Results of implementing a simplified version of Lukasse (1999) control scheme in comparison to the existing control scheme

\begin{tabular}{|c|c|c|c|}
\hline \multicolumn{2}{|c|}{ Control strategy } & Existing strategy & $\begin{array}{l}\text { Lukasse's strategy } \\
\text { (simplified) }\end{array}$ \\
\hline \multicolumn{2}{|c|}{$E Q[\mathrm{~kg} / \mathrm{d}]$} & 26254 & 20832 \\
\hline \multicolumn{2}{|c|}{$A E[\mathrm{kWh} / \mathrm{d}]$} & 13672 & 14332 \\
\hline \multicolumn{2}{|c|}{$D S[\mathrm{~kg} / \mathrm{d}]$} & 7530 & 4680 \\
\hline \multicolumn{2}{|c|}{$E Q$ costs [Euro/d] } & 787620 & 624960 \\
\hline \multirow{2}{*}{\multicolumn{2}{|c|}{$\begin{array}{cc}A E \text { costs } & {[\text { Euro/d] }} \\
D S \text { costs } & {[\text { Euro/d] }}\end{array}$}} & 984 & 1032 \\
\hline & & 4367 & 2714 \\
\hline \multirow{2}{*}{ 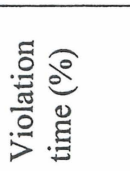 } & $\mathrm{NH}_{4}-\mathrm{N}$ & 50.9 & 89.2 \\
\hline & $T N$ & 8.6 & 0.5 \\
\hline
\end{tabular}


performance of this WWTP. Implementation of the benchmark was demonstrated through evaluation of some short- and long-term control strategies. Some of the interesting results obtained from this evaluation are the following: (i) influent flow splitting ratio, between the first and the fourth aerators of the ditch, had no significant effect on the TN concentrations in the effluent, (ii) RAS needed to be kept at maximum, (i.e. RAS = 1), and (iii) for the evaluation of the long-term control strategies, future benchmarks need to be able to assess settlers' performance.

\section{REFERENCES}

Abusam, A. and K.J. Keesman (1999), Effect of number of CSTR's on the modelling of oxidation ditches: steady state and dynamic analysis, Med. Fac. Landbouw. Univ. Gent, 64/5a, pp 91-94.

Abusam A., K.J. Keesman, G. van Straten, H. Spanjers and K. Meinema (2000a), Parameter estimation procedure for complex non-linear systems: calibration of ASM No.1 for N-removal in a full-scale oxidation ditch, in Proc. of the Watermatex2000, Gent, Belgium (2000).

Abusam, A., K.J. Keesman, G. van Straten and K. Meinema (2000b), Sensitivity analysis on oxidation ditches: the effect of variations in stoichiometric, kinetic and operating parameters on the performance indices, J. Chem. Tech. Biotech (in press).

Abusam, A., K.J. Keesman; G. van Straten and K. Meinema (2000c), Estimation of uncertainties in the performance indices of an oxidation ditch benchmark, J. Chem. Tech. Biotech (submitted).

Copp, J.B., (2000), Defining a simulation benchmark for control strategies, Water21, 1(1):44-49.

COST (2000), www.ensic.u-nancy.fr/COSTWWTP/Benchmark/Benchmark1.htm.

DHV Water (1993), DHV Water bv, Dossier G8112-10-001, Amersfoort, The Netherlands, (in Dutch).

EC (1999), Implementation of Council Directive 91/271/EEC of 21 May 1991 concerning urban waste water treatment, as amended by Commission Directive 98/15/EC of 27 February 1998: summary of the measures implemented by the member states and assessment of the information received pursuant to article 17 and 13 of the Directive, European Commission, Office for Official Publications of the European Communities, Luxembourg.

Henze, M., C.P.L. Grady, jr, W. Gujer, G. van R. Marais and T. Matsuo (1987), Activated sludge model no. 1, IAWQ scientific and Technical Report no. 1, IAWQ, London, U.K.

Keesman, K.J., H. Spanjers, P. Vanrolleghem, and J. Alex (1997), Benchmarks for control strategies in activated sludge plants, TMR Research Proposal No. ERB4061PL970020, Wageningen, The Netherlands.

Lindberg, C-F. (1997), Control and estimation strategies applied to the activated sludge process, Ph.D. thesis, Uppsala University, Sweden.

Lukasse (1999), Control and identification in activated sludge processes, Ph.D. thesis, Wageningen University, The Netherlands.

Lukasse, L.J.S. K.J. Keesman, A. Klapwijk and G. van straten (1999), A comparison of $\mathrm{NH}_{4} / \mathrm{NO}_{3}$ control strategies for alternating activated sludge processes, Wat. Sci. Tech 39(4):93-102

Metcalf \& Eddy (1991), Wastewater engineering: treatment, disposal and reuse, $3^{\text {rd }}$ ed, McGraw-Hill.

Schieland (1994), Hoogheemraadschap van Schieland, Procestechnologische gegevens: water en sliblijn, G25.2-32537, Rotterdam, The Netherlands, (in Dutch).

Spanjers, H., Vanrolleghem, P.A. Nguyen, K., Vanhooren, H., and Patry, G.G. (1997). Towards a simulation -benchmark for evaluating respirometry-based control strategies, Wat. Sci. Tech., 37(12):219-226.

Singman, J. (1999), Efficient control of wastewater treatment plants - a benchmark study, M.Sc. thesis, Uppsala University, Sweden.

Takács, I., G.G. Patry and D. Nolasco (1991). A dynamic model of the clarification -thickening process, Wat. Res. 25(10):1263-71.

UNEP (1999), Global environment outlook 2000, United Nations Environment Programme, Earthscan Publication Ltd, London.

Weijers, S. (2000), Modelling, identification and control of activated sludge plants for nitrogen removal, Ph.D. Thesis, Eindhoven University of Technology, The Netherlands. 